\title{
Results of systemic-to-pulmonary artery anastomosis for tricuspid atresia with reduced pulmonary blood flow
}

\author{
GIANCARLO CRUPI, OTTAVIO ALFIERI, GIUSEPPE LOCATELLI, \\ MASSIMO VILLANI, AND LUCIO PARENZAN \\ From the Department of Cardiac Surgery, Ospedali Riuniti, 24100, Bergamo, Italy
}

ABSTRACT Fifty-six patients with tricuspid atresia and decreased pulmonary blood flow received a systemic-to-pulmonary artery anastomosis as a preliminary operation. Thirty-five had a Waterston shunt, 12 a Blalock-Taussig anastomosis, and nine various other procedures. The age at operation ranged from 2 days to 10 years (median 4.5 months). Pulmonary atresia was present in eight newborn infants.

Four patients (7\%), all less than 3 months old, died in hospital from persistent severe hypoxia despite the palliative procedure. By actuarial methods, $93 \%$ of the survivors were alive at and after one year (longest follow-up: $9 \cdot 8$ years), while $83 \%$ had not required further palliation at and after four years from the first operation. None of the patients subsequently restudied had raised pulmonary pressure or resistances, and in most of them the pulmonary arterial tree was deemed adequate for the Fontan operation.

The natural history of patients with tricuspid atresia and decreased pulmonary blood flow is extremely poor. Without operation $20 \%$ of them die within the first year of life (Campbell, 1961; Keith et al, 1967). The creation of a systemic-topulmonary artery anastomosis early in life is therefore mandatory in most patients.

After the report by Fontan and Baudet (1971), the physiological correction of tricuspid atresia has become a reality, and any palliative operation should be performed with a view to the subsequent repair. Having these considerations in mind we have reviewed our entire experience with palliation of patients with tricuspid atresia and decreased pulmonary blood flow.

\section{Patients and methods}

Between January 1967 and January 197856 patients with tricuspid atresia, decreased pulmonary blood flow, and normally related great arteries underwent a systemic-to-pulmonary artery anastomosis in this department. Cardiac catheterisation and angiography were performed in each case. Balloon atrial septostomy was carried out only when a mean interatrial gradient of more than $3 \mathrm{mmHg}$ was present.

The patients ranged in age from 2 days to 10 응 years (median age: 4.5 months). Eight patients, all less than 1 month of age, also had pulmonary atresia. An ascending aorta-to-right pulmonary 3 . artery anastomosis was performed in 35 patients, 28 of whom were less than 6 months old. Twelve patients, all more than 6 months old had $a_{\circ}$ Blalock-Taussig anastomosis; four had an ascending aorta-to-main pulmonary artery anastomosis, three a Potts operation, one a Glenn shunt, and one a shunt from the ascending aorta to the mainos pulmonary artery with a Dacron tube (table 1). N When a direct anastomosis was performed between

Table 1 Types of shunts used

\begin{tabular}{|c|c|c|c|}
\hline \multirow[t]{2}{*}{ Type of shunt } & \multirow[t]{2}{*}{ No } & \multicolumn{2}{|l|}{ Age } \\
\hline & & $<6$ months & $>6$ months \\
\hline $\begin{array}{l}\text { Waterston } \\
\text { Blalock-Taussig } \\
\text { Others }\end{array}$ & $\begin{array}{r}35 \\
12 \\
9\end{array}$ & $\begin{array}{c}28^{*} \\
0 \\
4\end{array}$ & $\begin{array}{r}7 \\
12 \\
5\end{array}$ \\
\hline Total & 56 & 32 & 24 \\
\hline
\end{tabular}


the aorta and the pulmonary arterial tree, the diameter of the shunt stoma varied according to the patient's body weight.

All the survivors have been followed up periodically by direct physical examination, and for the purpose of this paper most patients were contacted and assessed either by direct examination or by a questionnaire sent to their families and to their physicians in March 1978. Seventeen patients underwent subsequent catheterisation and angiocardiography with a view to corrective operation or further palliation.

\section{Results}

There were four operative deaths, all of which occurred in patients less than 3 months old, giving an overall hospital mortality of $7 \%$ (table 2 ). An inadequate anastomosis with persistent severe hypoxia caused death in each case. All the survivors had a functioning surgically created systemic-to-pulmonary artery anastomosis and were discharged from hospital with improved arterial oxygen saturation.

There were three late deaths, all of which occurred within six months of operation. The causes of death were congestive heart failure from an excessively large anastomosis in one case and recurrence of severe hypoxia in the other two.

Seven patients received a further palliation 22 days to 4.7 years after the initial procedure, and one required a third systemic-to-pulmonary artery anastomosis (table 3). At the time of the last follow-up (median: 1.9 years), $38 \%$ of the survivors were asymptomatic, $52 \%$ had mild cyanosis, and $10 \%$ were definitely cyanotic and restricted in their physical activity.

Using actuarial methods, $93 \%$ of the survivors were alive at and beyond one year (longest followup: 9.8 years), while $83 \%$ did not require further
Table 2 Hospital mortality

\begin{tabular}{lrlcc}
\hline Age (months) & \multirow{2}{*}{ No } & \multicolumn{3}{l}{ Hospital mortality } \\
\cline { 3 - 5 } & & No & $\%$ & $C L+$ \\
\hline $0 \leq 1$ & 12 & 1 & $8 \%$ & $1 \%-26 \%$ \\
$>1 \leq 3$ & 9 & 3 & $33 \%$ & $15 \%-56 \%$ \\
$>3 \leq 6$ & 16 & 0 & $0 \%$ & $0 \%-11 \%$ \\
$>6 \leq 12$ & 7 & 0 & $0 \%$ & $0 \%-24 \%$ \\
$>12$ & 12 & 0 & $0 \%$ & $0 \%-15 \%$ \\
Total & 56 & $4^{*}$ & $7 \%$ & $4 \%-13 \%$ \\
\hline
\end{tabular}

* Three of these patients had a Waterston and one a Potts anastomosis. $\lceil 70 \%$ confidence limits.

Table 3 Reoperations

\begin{tabular}{|c|c|c|c|c|}
\hline \multirow[t]{2}{*}{ No } & \multicolumn{2}{|c|}{ First operation } & \multicolumn{2}{|c|}{ Second operation } \\
\hline & $\begin{array}{l}\text { Age } \\
\text { (months) }\end{array}$ & Type & $\begin{array}{l}\text { Age } \\
\text { (months) }\end{array}$ & Type \\
\hline $\begin{array}{l}1 \\
2 \\
3 \\
4 \\
5 \\
6^{*} \\
7\end{array}$ & $\begin{array}{c}0.7 \\
0.8 \\
0.8 \\
2.8 \\
5 \cdot 1 \\
5.2 \\
24\end{array}$ & $\begin{array}{l}\text { Waterston } \\
\text { Waterston } \\
\text { Waterston } \\
\text { Waterston } \\
\text { Waterston } \\
\text { Glenn } \\
\text { Blalock- } \\
\text { Taussig }\end{array}$ & $\begin{array}{l}1 \cdot 5 \\
30 \\
12 \\
19 \\
15 \\
58 \\
47\end{array}$ & $\begin{array}{l}\text { Potts } \\
\text { Blalock-Taussig } \\
\text { Blalock-Taussig } \\
\text { Blalock-Taussig } \\
\text { Blalock-Taussig } \\
\text { Blalock-Taussig } \\
\text { Open } \\
\text { valvotomy }\end{array}$ \\
\hline
\end{tabular}

*This patient also had a Dacron tube graft between the aorta and the main pulmonary artery at 7 years of age.

palliation at and beyond four years after the initial operation (see figure). Seventeen patients underwent subsequent catheterisation with a view to total repair or further palliation (mean interval between the initial shunt and the catheterisation: $28 \pm 14.6$ months). In 12 the pulmonary artery was entered during the study, and in all of them a normal pulmonary artery pressure and normal pulmonary vascular resistance was found irre-
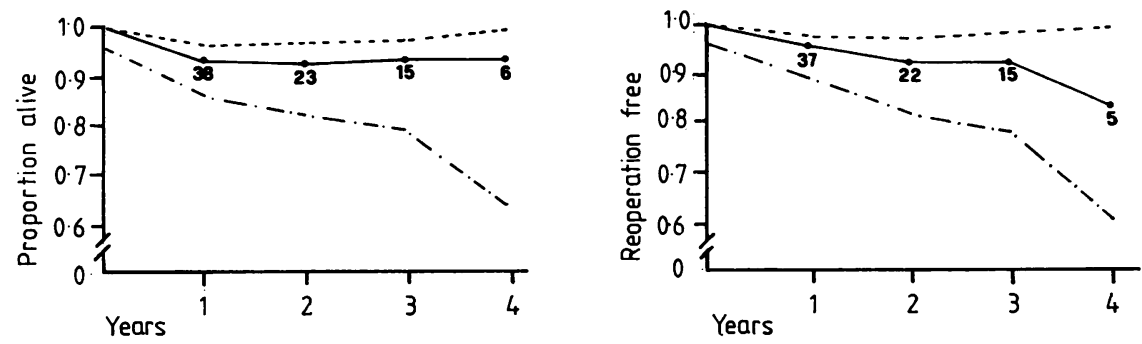

"Survival" and "reoperation free" actuarial curves for 52 patients with tricuspid atresia who survived first systemic-to-pulmonary artery anastomosis. Dashed lines represent $70 \%$ confidence bands. 
spective of the type of systemic-to-pulmonary artery shunt. In fact, among these 12 patients, six received a Waterston shunt, four an anastomosis between the ascending aorta and the main pulmonary artery, and two a Potts operation.

At angiocardiography, the pulmonary arterial tree was deemed adequate for the Fontan operation in all but two patients. Five, all less than 4 years old, needed a second palliative operation despite an adequately sized pulmonary artery as did the two children with an inadequate pulmonary arterial tree. Four have already been physiologically corrected, and six are awaiting repair.

\section{Discussion}

The outlook for patients with tricuspid atresia has changed since the introduction of the physiological type of repair proposed by Fontan and Baudet (1971). The criteria for corrective operation, however, are undoubtedly restrictive, the feasibility of the repair depending on the presence of an adequate pulmonary artery tree, low pulmonary vascular resistance, and reasonable ventricular function. Furthermore, ideal candidates for corrective operation should be at least 4 years old (Kreutzer, 1976). Therefore a satisfactory palliative procedure in the group of patients with reduced pulmonary blood flow should have the following features: (a) low mortality and morbidity, $(b)$ relief of symptoms for a reasonably long time, and (c) avoidance of pulmonary vascular obstructive disease.

The surgical mortality rate in published series of shunt operation for tricuspid atresia has been generally high, particularly in patients less than 6 months old (Subramanian et al, 1965; Deverall et al, 1969; Paul et al, 1969; Dick et al, 1975; Trusler and Williams, 1976; Williams et al, 1976). In our series the hospital mortality has been low and has occurred exclusively in patients aged below 3 months. It has been suggested that the type of palliative operation should be varied according to the age of the patients (Williams et al, 1976; Trusler and Williams, 1976), the Waterston shunt being usually preferred in the small patients.

In this series the Waterston shunt was the procedure of choice in patients less than 6 months old, whereas the Blalock-Taussig anastomosis has been used primarily for children above that age. None of the patients with a Waterston shunt who were reinvestigated by cardiac catheterisation was found to have increased pulmonary vascular resistance, and two of them underwent the Fontan operation successfully.
Our experience with the Potts shunt has been $\stackrel{+}{\vec{F}}$ small but also gratifying from this point of view: the survivors are alive at five and nine years from the first operation, and both are candidates for $\frac{\bar{\sigma}}{\bar{s}}$ total correction. Similarly, we have obtained good $\frac{\bar{s}}{\vec{D}}$ long-term results with a direct anastomosis be- $\mathbb{\mathscr { Q }}$ tween the ascending aorta and the main pulmonary artery; among the four patients who had $\vec{\circ}$ this type of shunt, two have already undergone a successful Fontan procedure and the remaining two are awaiting this type of repair.

As regards the duration of the shunt our actu- $\vec{x}$ arial curves show that $83 \%$ of the patients did not $\underset{\omega}{\omega}$ have further palliation at and after four years $\stackrel{t}{\omega}$ from the first operation. Patients who required is early palliation, who usually had either pulmonary $\varnothing$ atresia or a severely narrowed pulmonary outflow 욱 tract with small pulmonary arteries, were the most $\overrightarrow{ }$ likely to require another palliative operation before $\subseteq$ reaching the ideal age of repair.

In conclusion we think that far more attention $\vec{\bullet}$ should be paid to the palliation of patients with tricuspid atresia and decreased pulmonary blood flow. Although the criteria for corrective operation are selective, the creation of the appropriate systemic-to-pulmonary artery anastomosis may allow total repair in most of these otherwise hopeless patients.

\section{References}

Campbell, M (1961). Tricuspid atresia and its prognosis with and without surgical treatment. British Heart Journal, 23, 699-710.

Deverall, P B, Lincoln, J C R, Aberdeen, E, Bonham- ֻ Carter, R E, and Waterston, D J (1969). Surgical o management of tricuspid atresia. Thorax, 24, 239245.

Dick, M, Fyler, D C, Nadas, A S (1975). Tricuspid atresia: clinical course in 101 patients. American Journal of Cardiology, 36, 327-337.

Fontan, F, and Baudet, E (1971). Surgical repair of $\frac{D}{O}$ tricuspid atresia. Thorax, 26, 240-248.

Keith, J D, Vlad, P, and Rowe, R D (1967). Heart N Disease in Infancy and Childhood, 2nd edn. Macmillan, New York.

Kreutzer, G (1976). Recent Approaches to Tricuspid N Atresia. The Child with Congenital Heart Disease after Surgery, edited by B S L Kidd and R D Rowe, pp 85-97. Futura, New York.

Paul, M H, Greenwood, R D, Cole, R B, and Muster, A J (1969). Aortic pulmonary anastomosis for tri-: cuspid atresia. Circulation, 39, suppl III, 160.

Subramanian, S, Carr, I, Waterston, D J, BonhamCarter, R E (1965). Palliative surgery in tricuspid $\underset{\mathbb{D}}{\mathbb{Q}}$ atresia. Circulation, 32, 977-980.

Trusler, G A, and Williams, W G (1976). Long-term Results of the Glenn Procedure for Tricuspid 
Atresia. The Child with Congenital Heart Disease after Surgery, edited by B S L Kidd and R D Rowe, pp 79-84. Futura, New York.

Williams, G W, Rubis, L, Fowler, R S, Rao, M K, Requests for reprints to: Dr G C Crupi, Department

Trusler, G A, and Mustard, W T (1976). Tricuspid of Cardiac Surgery, Ospedali Riuniti, 24100-Bergamo. atresia: Results of treatment in 160 children. American Journal of Cardiology, 38, 235-240. 